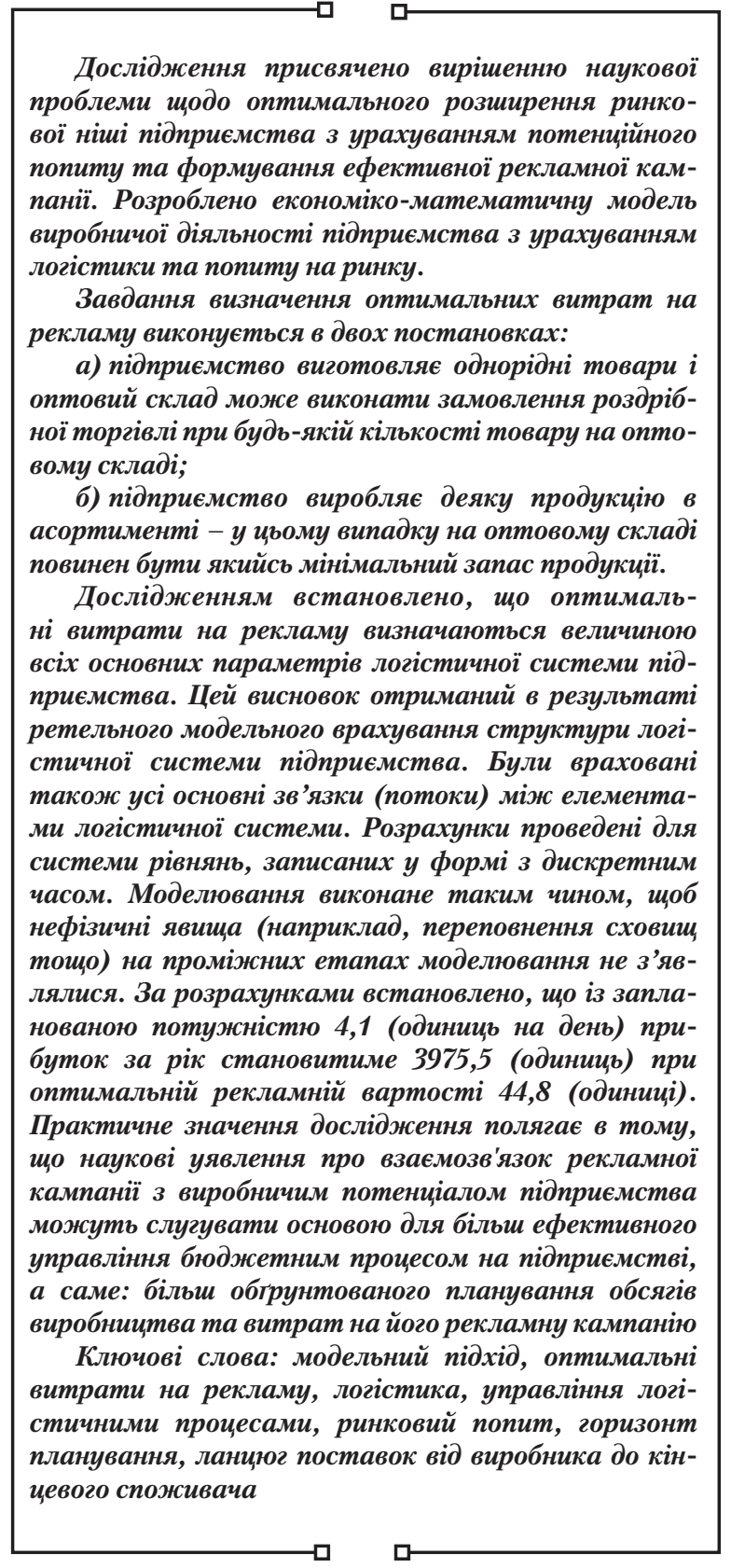

UDC $338.2: 659.1$

DOI: $10.15587 / 1729-4061.2020 .201087$

\section{MANAGEMENT OF AN ADVERTISING CAMPAIGN BASED ON THE MODEL OF THE ENTERPRISE'S LOGISTIC SYSTEM}

\author{
Y. Sherstennikov \\ Doctor of Economic Sciences, Associate Professor \\ Department of Economic Cybernetics \\ Oles Honchar Dnipro National University \\ Gagarina ave., 72, Dnipro, Ukraine, 49010 \\ E-mail:hm001@ukr.net \\ T. R u d y a n ov a \\ $\mathrm{PhD}$ \\ Department of Computer Science and \\ Software Engineering* \\ E-mail: rudyanova@i.ua \\ L. B a r a n n y k \\ Doctor of Economic Sciences, Professor \\ Department of Social Security and Tax Policy* \\ Email: baranniklb@gmail.com \\ V. Dat se n k o \\ $\mathrm{PhD}$, Associate Professor \\ Department of Entrepreneurship, \\ Marketing and Enterprise Economics* \\ E-mail: vd20042011@gmail.com \\ L. Novikova \\ $\mathrm{PhD}$, Associate Professor \\ Department of Banking and Financial Services* \\ Email: novikova_If@ukr.net \\ *University of Customs and Finance \\ V. Vernadskoho ave., 2/4, Dnipro, Ukraine, 49000
}

\section{Introduction}

In a competitive market, every enterprise seeks to minimize costs and maximize profits. This requires a coordinated work of all its links. The more large-scale the enterprise is, the more difficult it is to coordinate the activities of all its structures, including the logistics system. The latter, according to J. Forster, is a system of reservoirs interconnected by material, financial and information flows. Shortcomings in the management of logistics processes conceal a high risk of loss of profit by the enterprise. This can be prevented using a mathematical solution, that is, to develop a mathematical model that can solve the problem of optimal management of the enterprise's logistics system. Based on such a model, a wide range of problems can be solved: from developing a new logistics project to optimizing a new or existing project advertising campaign. Of course, such a model must contain a large number of exogenous parameters in order to take into account the diversity of both the production structures themselves and the influence of external economic factors.

Another equally important task of the enterprise is the implementation of an effective advertising campaign, which would also comply with the principle of optimality. It is possible to solve the problem of optimization of an advertising campaign of an enterprise by applying the methodology of calculating the optimal costs for an enterprise advertising campaign and taking this into account when modeling. 
Most scientific approaches are focused on the detailed study of individual links and processes in the logistics system, and in fact, after J. Forster [1], no one has tried to model the entire supply chain from production to delivery to the final consumer.

The lack of such research and the tasks outlined above highlight the practical demand for this study and its relevance. Research on these issues will be quite useful in the application plan, since it will allow any enterprise, taking into account its production specifics and goals of the corporate strategy, to solve the problem of optimization; in the scientific field - for further development and research in the field of logistics systems management in different sectors of the economy.

\section{Literature review and problem statement}

With the development of the digitalization of the economy, enterprises are actively resorting to advertising over the Internet, but they are not always professionally competent. The role of Internet advertising, convenience and forms of influence on users of advertising are considered in the work [2]. This paper provides an overview of empirical research over the last decade, as well as questions regarding the use of basic theoretical knowledge needed to analyze and develop advertising on the Internet; determines which characteristics of online advertising are most important in terms of understanding and supporting certain specific influences on its users. Particular attention is paid to analyzing the behavior of consumers who have visited the firm's website many times [3]. However, there is no study to answer such an important question: how can an enterprise optimize its advertising costs even in such a relatively inexpensive way compared to others, so it can be assumed that such a problem exists and therefore needs further development.

In the work [4], the "method of fuzzy organization of ranking preferences for evaluating enrichment" (fuzzy PROMETHEE method) is presented, which allows evaluating potential suppliers by a number of criteria. The uniqueness of this method lies in the fact that it can be used in situations with different materials and with a different number of criteria. Despite the advantages and possibilities of this method, it cannot be applied to solve the above problems of optimal modeling of an advertising campaign taking into account logistics processes.

Buying (or real-time bidding) has recently become the fastest growing area in online advertising. In the work [5], a research group made an "empirical analysis and measurement of a production ad exchange". The authors concluded that it is necessary to develop optimization algorithms that take into account such factors as temporary behavior, frequency, and relevance of advertising, which were not properly considered by other authors in previous studies. It is quite obvious that one can take into account the effect of so-called unipolar factors, such as psychological, financial (cost), organizational, etc. It is too difficult to consider different factors. Therefore, this paper is an attempt to investigate the problem of optimization, combining temporal behavior (psychological factor) and frequency of advertising (organizational factor). It is undoubted that in the future such studies will be of great importance for the effective practical operation of the campaign.
Several works suggest some models of advertising campaigns. The paper [6] discusses joint advertising of a manufacturer and a retailer, as well as prices in a dynamic stochastic supply chain.The authors have developed the model "the supply chain problem as a stochastic Stackelberg differential game whose dynamics follows Sethi's stochastic sales advertising model". Their model allows reaching the situation where advertising becomes optimal for the manufacturer. However, it does not take into account such an aspect of the problem as addressing the issue of optimization of the advertising campaign in the light of logistics operations. Therefore, there is a certain scientific and practical need to create a model that will help in real time to combine such parameters of the production activity of the enterprise, such as advertising, logistics, and will be focused solely on everyday goods.

The paper [7] presents a hybrid pricing strategy based on CPM (cost-per-mile) and CPC (cost-per-click) variables. The authors propose a multi-purpose model to build pricing strategies and maximize web portal revenue while minimizing the cost to the advertiser. This is a multidimensional multi-purpose optimization model. The NSGA-II multiobjective optimization algorithm is used to create the new model. However, it is not always appropriate, for example, to solve an optimization problem based on a dynamic factor such as demand. The idea behind this work is primarily to maximize results, but the growing proportion of advertising content on websites often leads to negative side effects that also need to be explored separately.

The work of the research team [8] presents the concept of a methodology for measuring advertising networks. This work is useful in that the authors propose new indicators of various advertising properties, in particular, a high level of noise from the distribution of advertising, and also analyze how information on user profiles is used in three types of advertising practice (search, contextual and social).

Recently, the model approach has been actively used in the economics of sociology. The focus of the paper [9] is a model of the impact of some behavior factors (according to the authors, "attitudinal antecedents") on the frequency of green purchase by consumers. Their study is based on survey data of 419 undergraduates and analyzed using a system of structural equations. This model is named "Path Model of Attitudinal Antecedents of Green Purchase Behavior". In other words, it is based on a step-by-step study of the socalled direct and indirect predecessors, that is motives that affect the behavior of the consumer of green products.

The next direction of optimization modeling is related to the solution of issues of joint (or cooperative) advertising in the manufacturer - retailer supply chain. The work [10] is devoted to a joint strategy in an advertising campaign and pricing model in the supply chains of manufacturers and retailers. For the study, areas such as manufacturing and retail were selected. The authors analyze four different models, based on three non-cooperative games (Nash, Stackelberg and Stackelberg producer) and one cooperative game. They determine the optimal strategies for joint advertising and pricing for two firms mainly analytically and in one case using numerical modeling.

Then the results are compared, first of all, profit, for all cases. This approach allows in a particular case of cooperation to find out when the profits are the highest for the seller and for the manufacturer, and how they should share the additional common profit achieved through the transition 
to cooperation. Scientists solve this problem using the Nash negotiation model. That is, this study illustrates, on a specific example, how certain techniques can be used, what is its practical value.

A somewhat different approach to cooperative advertising is outlined in the paper by the research group [11], which uses two game-theoretical models to analyze the problem of joint advertising. These authors also focus their research on such an aspect as "supply chain between a manufacturer and a retailer". At the same time, the authors disregard factors such as national branding and local advertising. They prove that the change of dominance that has come from the transition from manufacturers to retailers weakens the relationship between leader and follower and becomes a so-called "simultaneous move-game". Of course, the authors, using game theory, cannot account for all situations related to joint advertising. The paper proves that game theory is an important tool in the analysis of supply chain problems with multiple agents pursuing either shared or contradictory goals.

In the paper [12], scholars consider using a wholesale pricing and profit sharing (WPPS) scheme to coordinate supply chains within a mean variance (MV). Using the mean variance method, the authors solve several problems: analytically determine the necessary and sufficient conditions for coordinating a centralized supply chain using WPPS; prove the unique balance of the Stackelberg game with WPPS in the decentralized case. The authors consider an "information asymmetric case" in which a retailer can benefit by pretending to be more risk-averse. This is a farfetched case, but it deserves consideration as an option.

Currently, the emphasis of economic science research is shifting from the study of individual production systems to integrated logistics systems that provide the entire production cycle from the purchases of goods to the delivery of finished products to the consumer. General difficulties arise with the identification of models. Lack of information leads to significant errors in the justification of models. Therefore, one of the works of scientists [13] provides an overview of the literature on discrete event modeling that describes the complex supply chain. The models described allow us to study the dynamics of the supply chain and to develop alternative strategies.

Gaps in modern logistics research exist regarding simulations of all elastic and multimodal supply chains. The risks connected with various forms of supply are not fully studied. There are some mathematical methods, which help partially eliminate these shortcomings. For example Tecnomatix Plant Simulation. It is an object-oriented 3D program used to simulate discrete events. The possibility of using Tecnomatix Plant Simulation (by Siemens) in logistics is the main objective of the paper [14].

Many aspects of planning the activities of enterprises in market conditions are sufficiently investigated. Thus, the purpose of the paper [15] is to create a reference model of business processes for the supply chain, which would take into account the special conditions when moving perishable goods. The paper [16] provides a detailed overview and analysis of logistics operations and their management. This paper deals with all aspects of product promotion - from manufacture to consumer satisfaction. In the paper [17], a dynamic model of market pricing and production was developed, which allows to determine the general patterns of production and technological specifics of the economic system. The theoretical basis for constructing the model is balance relations, combining the approaches of Léon Walras and Alfred Marshall to describe the dynamics of prices and volumes of industrial products in the market of one product. The synthesized mathematical model is a system of two linear differential equations for determining the price and volume of goods in discrete time. For this dynamic system, the stability conditions for the equilibrium position are obtained and the corresponding parametric analysis is performed. The authors of these works, modeling the production situation on the principle of "condition-result", solve specific problems that help businesses navigate in a rapidly changing market environment.

Using agent-based modeling methods, consumer behavior models of similar products were constructed and analyzed in the paper [18]. The Ferber reactive agent model is used to determine the behavior of agents within the simulation model. Reactive agent models are characterized by the application of the concept of states and transitions, as well as behavioral mechanisms such as stimulus-response. The model presented well describes the situational aspect of the behavior of the agent-consumer, but does not take into account the influence of advertising on the agent's behavior, as well as such condition as the release of the same products in the range, for example, shoes of different sizes, which requires further development of the model.

The study [19] is devoted to an analysis of approaches to modeling industrial enterprise management processes. The authors argue that in an unstable market environment, the most effective is an adaptive approach to enterprise management. It is characterized by the use of the system of quantitative and qualitative research methods, probabilistic decision-making methods, information systems, models and methods that have a single information base and are able to adapt to changing conditions. In order to prevent early destabilization of the system's functioning within the mechanism of compensation regulation, the authors proposed the use of three known mathematical models and conclude that this approach allows ensuring the effectiveness of the decisions made in accordance with the situation, which occurs both in the external and internal environment of the enterprise. However, this is a controversial conclusion, since everything is considered for a hypothetical enterprise and does not take into account many internal factors that can negatively affect the result. With respect to the external environment, there is such a significant factor in influencing the adaptation of the enterprise as demand, which is not taken into account in the formulas presented. Alternatively, the proposed models in this context are noteworthy.

Leading experts in the field of logistics investigate logistics problems in various aspects. However, in these works the relationship between the parameters of the logistics system (LS) of the enterprise and the current characteristics of the consumer market is not sufficiently disclosed: potential demand for products, rates of consumption of products. This drawback of modern theory complicates the study of the influence of an advertising campaign on the economic efficiency of an enterprise.

The paper by the team of authors [20] proposes a model that, from a fundamental point of view, meets the stated requirements. This model allows to take into account the detailed characteristics of the market. But at the same time, the model has a drawback; it leads to unstable solutions in a wide range of parameters. The authors of the paper [21] proposed a method for eliminating this drawback. Their method 
is based on averaging the rate of sales and transportation of goods over a period.

Thus, in summarizing the scientific papers on this topic discussed in this section, we should note that they present different scientific ideas that are in their own way useful and of practical value. However, they do not reveal the problems of optimal expansion of the market niche of the company, taking into account the potential demand and, accordingly, the formation of an effective advertising campaign.

\section{The aim and objectives of the study}

The aim of the study is to solve the problem of determining the optimal cost for an advertising campaign, in which the company will receive the maximum net income. This will allow the company to plan an advertising campaign, matching it with the market demand and parameters of the logistics system.

To achieve this goal, the following objectives were set:

- to develop a method of calculation that reflects the impact of enterprise spending on advertising while increasing the number of potential consumers of products;

- to draw up a system of equations for the proposed scheme of the logistics system of the enterprise, which allows to determine the main characteristics of all its chains, starting from the production line and ending with the delivery of products to the end consumer throughout the planning horizon;

- on the basis of the obtained system of equations to develop a method of optimization of the advertising campaign of the enterprise and to perform numerical calculations of model parameters with discrete time;

- to take into account the impact of random factors on the cost effectiveness of an advertising campaign and determine at what parameters of random factors that influence can be neglected.

\section{Scheme of enterprise logistics and modeling of advertising campaign}

The research examines an enterprise which logistics corresponds to the scheme shown in Fig. 1. The logistics system consists of seven elements: four tanks (according to Forrester terminology) - K, $S, R \mathrm{i}(Q, V)$, and three transport links $-y, s o, r$. In the calculations, it is assumed that the enterprise is fully provided with current assets and does not have problems with transport.

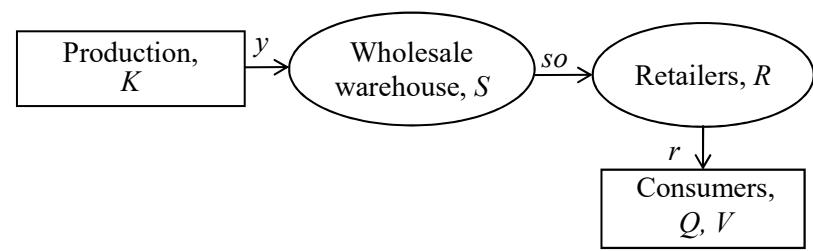

Fig. 1. Scheme of the enterprise's logistics

Working in a competitive market requires the enterprise's management to pay attention to expanding the market niche of the enterprise or at least maintaining it at an appropriate level. One of the effective means to achieve this goal is conducting a periodic or continuous advertising cam- paign. Therefore, the construction of the model begins with the mathematical description of the effect of advertising on the potential demand $Q$.

Let's assume that the impact of advertising on the current potential demand $Q(t)$ corresponds to the additive contribution

$$
Q(t)=Q n+Q r(t)
$$

where $Q n$ is the value of potential demand in the absence of advertising, $Q r(t)$ is the contribution of advertising to the potential demand.

The increase in the potential demand $\Delta Q r$ will be proportional to the product of the number of consumers who have not yet got acquainted with the advertising of the goods $(Q m-Q r)$ (where $Q m$ is the maximum possible number of potential consumers of the item) by the advertising costs $\Delta Z$ :

$$
\Delta Q r=\frac{1}{t z}(Q m-Q r) \cdot \Delta Z
$$

where $\frac{1}{t z}$ is the proportionality coefficient ( $t z$ is a constant depending on market conditions and the item considered).

Proceeding to differentials, we can obtain the following equation:

$$
\frac{\mathrm{d} Q r}{\mathrm{~d} Z}=\frac{(Q m-Q r)}{t z}
$$

Since with zero advertising costs, the potential demand $Q r$ due to advertising has also the zero value $Q r=0$, equation (2) needs to be solved under the initial condition $Q r(0)=0$. Then equation (2) has the following solution:

$$
Q r(Z)=Q m^{*}(1-\exp \{-Z / t z\}) .
$$

Equation (3) means that with the cost of advertising $Z$, the value of potential demand due to the advertising campaign $Q r(Z)$ will be achieved. Equation (3) with $Q m=1,000$ and $t z=30$ results in the dependence of the maximum value of potential demand on the costs for the advertising campaign as shown in Fig. 2.

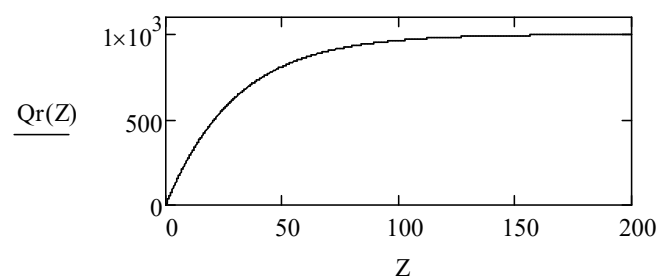

Fig. 2. Dependence of the maximum potential demand $\operatorname{Qr}$ on advertising costs $Z$ ( $\$$ per period of time)

Fig. 2 shows the curve of the maximum potential demand $Q r$ which will be achieved with constant advertising costs $Z$ (\$ per period of time).

In the future, the project of length $\mathrm{T}$ (planning horizon) will be considered. A system of equations for a discrete time $i(i=0,1,2, \ldots, T)$ will be written.

The behavior of potential demand due to an advertising campaign is described in the discrete-time model by the vec- 
tor $Q_{i}$. Applying the same reasoning which is brought to formula (3) to the vector $Q_{i}$, we can get the following equation:

$$
Q_{i+1}=Q r(Z) \cdot(1-\exp \{-i / t r\}) .
$$

Formula (4) means that the contribution to potential demand due to the advertising campaign $Q_{i}$ is described by the first-order lag model [1].

\section{System of equations describing the operation of the enterprise logistics system}

Let's confine ourselves to considering an advertising campaign that is defined by equations (1)-(4). Then other equations of the model corresponding to the scheme in Fig. 1 can be written down as follows:

1) the change in the demand $Q_{i}$ for products on the market is an input impact for the enterprise whose task is to align its output with the demand:

$$
r_{i+1}=n \cdot R_{i} \cdot\left(Q_{i}-V_{i}\right),
$$

where $r_{i}$ is the sales rate (unit per period of time) in the $i^{\text {th }}$ period; $n$ is the parameter which is determined by the average sales level for the previous quarter (or year); $R_{i}$ is the inventory level at the retail in the $i^{\text {th }}$ period; $V_{i}$ is the inventory level in the hands of consumers (not consumed yet);

2) the inventory level at the retail is determined by the recurrence formula:

$$
R_{i+1}=R_{i}+T d \cdot\left(s o_{i}-r_{i}\right)
$$

where $s o_{i}$ is the rate of delivery (units per period) from the wholesale warehouse to retailers; $T d$ is the period of discretization of the model, the time interval between decisions.

3 ) the level $R_{i}$ should be within the limits of $0 \leq R_{i} \leq R m$, where $R m$ is the maximum possible inventory level at the retail. The requirement is described by the following formula for the rate of delivery from the wholesale warehouse to retailers:

$$
s o_{i+1}=\min \left[r_{i} \cdot\left(1+\frac{R_{m}-R_{i}}{R_{m}}\right), \frac{R_{m}-R_{i}}{T d}, \frac{S_{i}}{T d}\right],
$$

where $S_{i}$ is the inventory level at the wholesale warehouse.

Some publications [21,22] substantiates the need for averaging when performing the calculations with the proposed model:

$$
\overline{S O}_{i}=s o_{i-p s}^{i},
$$

where $p s$ is the averaging time interval.

4. The production rate $y_{i}$ is determined by the following formulas:

$$
y_{i+1}=\left(y_{i}+\frac{y m-y_{i}}{t y}\right) \cdot\left\{\begin{array}{cc}
1, & \text { if } S_{i}<S m-2, \\
0.5 & \text { otherwise }
\end{array}\right.
$$

where $y_{i}$ is the production capacity in the $i^{\text {th }}$ period; $y m$ is the planned value of the production capacity; $\mathrm{Sm}$ is the maximum inventory level at the wholesale warehouse. These formulas allow avoiding the overflow of the wholesale.
5 ) the inventory level at the wholesale warehouse $S_{i}$ is calculated using the following formula:

$$
S_{i+1}=S_{i}+T d \cdot\left(y_{i}-s o_{i}\right),
$$

where $y_{i}$ is the rate of goods flow, which goes to the wholesale warehouse from the enterprise.

6 ) to determine the net income of the enterprise, the following formulas are applied:

$$
M_{i}=(1-k p) \cdot\left[\begin{array}{l}
(1-k a d) \cdot p \cdot r_{i}- \\
-p \cdot c \cdot y p_{i}-z S \cdot S_{i}- \\
-z R \cdot R m-q z \cdot Z
\end{array}\right]-B\left(y_{i}\right),
$$

where $c$ is the share of the prime cost in the price for products; $p$ is the price for a production unit; $z R, z S$ are the costs for the storage of a production unit during one period at the retail and wholesale warehouse, respectively; $k p$ is the income tax rate; $k a d$ is the value-added tax rate; $q y$ is the cost of 'including', 'excluding' a unit of production capacity.

$$
B\left(y_{i}\right)=0 \text {, if } i<1, B\left(y_{i}\right)=q y\left|y_{i}-y_{i-1}\right| \text {, if } i \geq 1 \text {. }
$$

Time will be treated as a discrete variable $i(i=0,1,2, \ldots, T)$ $[23,24]$. Let's further analyze the project of length $\mathrm{T}$ (planning horizon). Calculations for model (5)-(12) are performed with the following values of its parameters:

$$
\begin{aligned}
& R m=80, t y=15, Q=1,200, k 1=0.33, \mathrm{~d} T=1, \\
& t z=30, t Q=10, Q m=1,000, \\
& Q n=1,000, q S=0.88, Z=54, \\
& k 2=0,2, S_{0}=100, S m=200, \\
& n=0.00005, y m=6, q z=0.35, \\
& k p=0.25, k a d=0.06, c=0.6, p=10, z=0.3 .
\end{aligned}
$$

\section{Calculations of parameters of the optimal advertising campaign}

Let's consider a problem of bringing production capacity into line with current product demand in the following two cases:

A) the enterprise makes homogeneous goods and a wholesale warehouse can fulfill the retail order for any amount of goods in a wholesale warehouse $S_{i}$;

B) the enterprise makes some products in assortment (for example, footwear). In this case, in a wholesale warehouse there should be some minimum stock of products so that the wholesale warehouse could always fulfill the retail order.

Before to start the formal solution of the problems, it is necessary to be convinced that model (1)-(9) leads to reasonable results.

Let the maximum productivity of the enterprise (see equation (9) be $y m=4.6$; the number of consumers in the absence of advertising $Q n=1,000$; the cost of advertising is $Z r=50$. For such values, according to the equation (1) (at $t z=10$ ), the following dependence can be obtained (Fig. 3). 


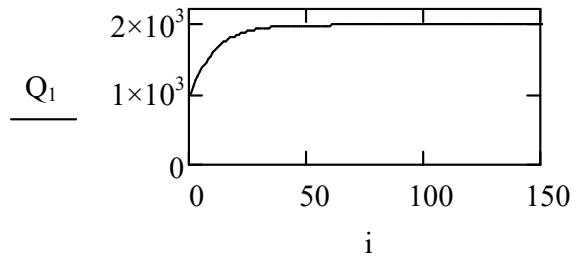

Fig. 3. Current value of potential demand

The results shown in Fig. 4, 5 will be received for the planning horizon $T \equiv i m=365$.

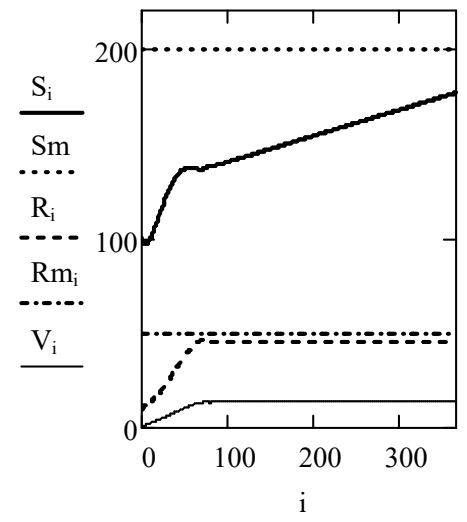

Fig. 4. Current quantity of the goods in a wholesale warehouse, in retail trade and goods at the consumer

Fig. 4 shows the maximum quantity of goods in the retail network. Supposedly that it is the period function, but we will be limited to the case $R m_{i}=$ const.

Fig. 5 shows the dynamics of the basic rates in the logistics system in the calculation with the use of averaging (8).

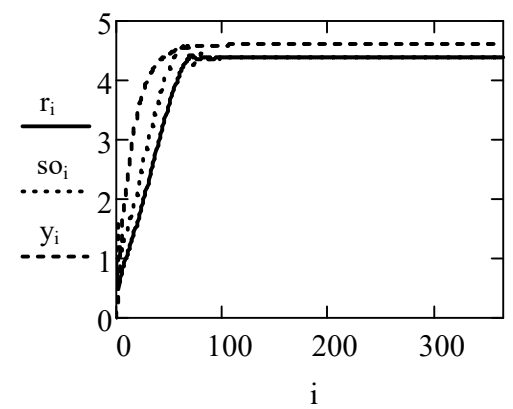

Fig. 5. Current values of production rates $y_{i}$, sales $r_{i}$ and delivery rates from the wholesale warehouse to the retail trade soi when using averaging

The lag of the sales rate and delivery rate from the production rate during the first 20 periods (days) is due to the fact (Fig. 5) that in these periods the goods are mainly supplied to the wholesale warehouse, not to retail. The rate of sales and deliveries will be equal to the rate of production over the following periods, as shown in Fig. 5. In the model, a balance model of goods is executed, according to which the change in the quantity of goods at all levels is considered as the difference between manufactured and sold goods.

$$
\begin{aligned}
& \sum_{i=0}^{T-1}\left(y_{i}-r_{i}\right)=36.463, \\
& S_{T}+R_{T}-\left(S_{0}+R_{0}\right)=36.463, \quad(\mathrm{~T}=365) .
\end{aligned}
$$

The dynamics of the rate of delivery from the wholesale warehouse to the retail trade without the use of averaging (8) is shown in Fig. 6 for comparison.

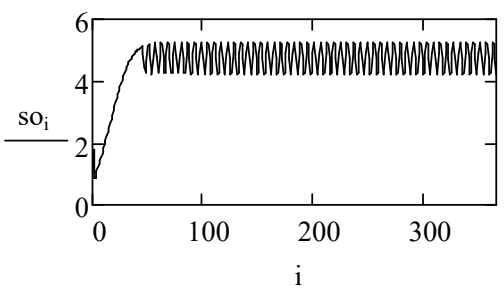

Fig. 6. Current values of the rate of delivery from a wholesale warehouse to the retail trade $s ;$ without averaging

It is necessary to note that economic indicators (current profit, etc.), calculated on models with and without averaging, practically coincide. The model taking into account averaging will be used in further calculations.

The problem A) is actually reduced to the optimization of the advertising campaign if the parameters of the logistics system are connected by the equations (5)-(12). The profit of the enterprise received for the time interval $\mathrm{T}$ (planning horizon) is chosen as a criterion function of the optimization problem. The problem with a particular optimization problem is to maximize the criterion:

$$
F 11(Z r)=\sum_{i=1}^{T} M_{i} \rightarrow \max
$$

The constraint system for the optimization problem (13) is the system of the equations of the model (5)-(12).

Fig. 7 shows the dependence of the total profit for the entire duration of the project (13) on advertising costs. From Fig. 7 it can be seen that the optimization problem can have a solution, since the function has an extremum for a certain sense of cost.

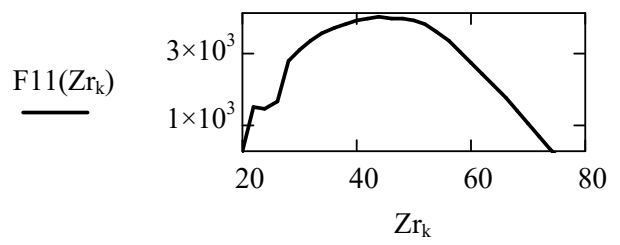

Fig. 7. Dependence of the criterion function on advertising expenses

The numerical optimization method (at $y m=4.1$ ) has the following result: at optimum advertising costs $Z r_{-} o p t=$ $=44.8$ the target function reaches the maximum value $F 11\left(Z r_{\_} o p t\right)=3975.5$.

Thus, Fig. 7 illustrates the solution of the optimization problem (13). In the absence of an advertising campaign $(Z r=0)$, the calculations lead to a negative profit $F 11(0)=-966$.

Therefore, the effectiveness of the advertising campa$\operatorname{ign}\left(E F_{\text {advert }}\right)$ is:

$$
E F_{\text {advert }}=\frac{F 11(Z r)-F 11(0)}{F 11(Z r)} \cdot 100 \%=351 \% .
$$

Calculations for the presented example have shown that the advertising campaign can be rather effective. Fig. 8, 9 show the dynamics of the current quantity of goods in a 
wholesale warehouse and in a retail network for the optimum solution.

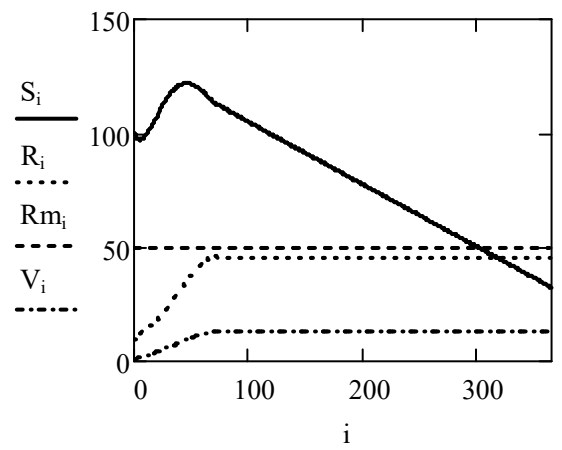

Fig. 8. Situation, as in Fig. 4, but for the optimum solution

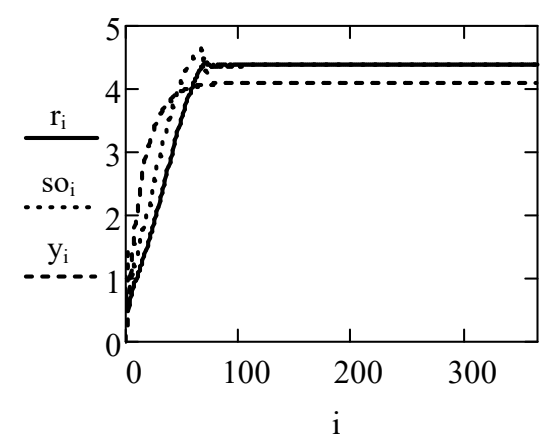

Fig. 9. Situation, as in Fig. 5, but for the optimum solution

Comparison of Fig. 5 and Fig. 8 shows that the rates of deliveries and sales for the optimum solution after 80 periods considerably exceed the rates of manufacture. This leads to a decrease in the stocks of goods in the wholesale warehouse (Fig. 8).

Let's pass to case B). For homogeneous goods, it is sufficient that there be some stock of goods in the wholesale warehouse, and the flow of goods into the retail network will decrease when the stock of goods in the wholesale warehouse tends to zero. In a case when the enterprise makes products in assortment, for example, footwear of various sizes, while reducing the stock of goods in the wholesale warehouse, some retail outlets will not always be provided with all sizes of shoes. Let's consider a situation where stocks in the warehouse are below a certain critical value, then the wholesale warehouse cannot fulfill all orders of the retail network, and this will lead to an effective reduction in the flow of goods from the wholesale warehouse. Now the equation (9) should be replaced by the following:

$$
\begin{aligned}
& s o(t)=\min \left[\begin{array}{l}
r_{i}^{*}\left(1+\frac{R m-R(t)}{R m}\right), \\
R m-R(t), S_{i}
\end{array}\right] \times \\
& \times\left\{\begin{array}{l}
1, \text { if } S_{i}>S c, \\
\frac{S_{i}}{S c}, \text { otherwise. }
\end{array}\right.
\end{aligned}
$$

Let $S c$ equals to an initial stock in the wholesale warehouse. Then the solution of the optimization problem (13) leads to the dependencies shown in Fig. 10-12.

By numerical calculations, it is found that the function $F 11(Z r)$ has in this case a maximum at $Z r_{-} o p t=36.8$, thus the criterion function reaches the maximum value Fig. 10 illustrates the solution of the optimization problem (13).

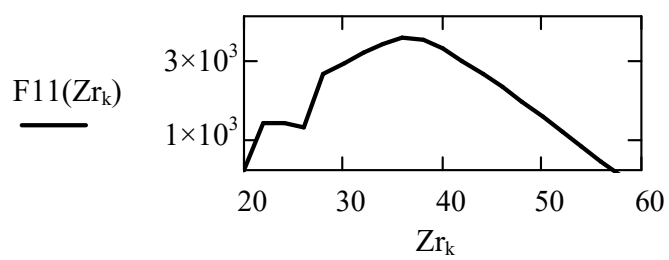

Fig. 10. Dependence of the criterion function on advertising expenses at minimum quantity restriction in a wholesale warehouse

Fig. 11, 12 show the dynamics of stocks for the optimum solution when replacing the equation (9) with (14).

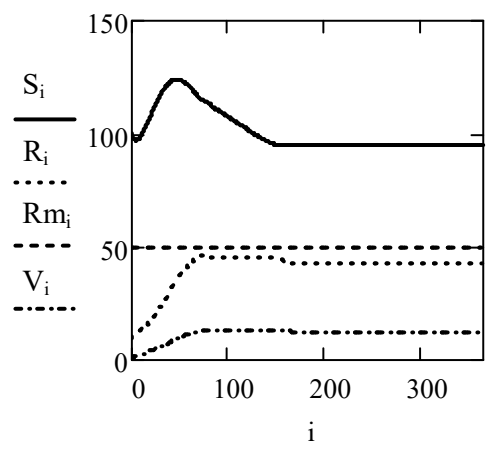

Fig. 11. Current quantity of goods in the wholesale warehouse, retail trade and goods in the hands of the consumer, taking into account the formula (14)

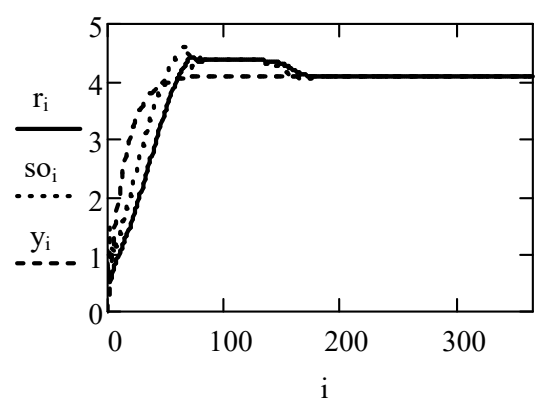

Fig. 12. Current values of production rates $y_{i}$, sales $r_{i}$ and delivery rates from the wholesale warehouse to to the retail trade $s_{i}$, taking into account the formula (14)

Fig. 11 shows that the quantity of goods in the wholesale warehouse $S_{i}$ increases during the first 50 periods. This fact becomes clear from Fig. 12, which shows that in the first 50 periods the production rate $y_{i}$ exceeds the rate of delivery from the wholesale warehouse to the retailer $s o_{i}$.

\section{Accounting for the influence of random factors on the economic effectiveness of an advertising campaign}

The external environment can bring significant excitement to the operation of the logistics system (LS). First, these perturbations can be brought in flows of LS. Therefore, the transport flows $s o(t)$ may experience random fluctuations depending on the availability and condition of vehicles. The flow of produced goods $y(t)$ - depending on the operation 
rate of a production link. The flow of sales $r(t)$ of goods of day-to-day consumption is stochastic by nature. Consider the changes that will be made when considering the stochastic factor in the LS flow coefficients in the model.

The adequate description of LS operation should consider the presence of "noise" in the flow characteristics. To reflect the fact that the sales indicator is stochastic in equation (5), it is necessary to introduce a random coefficient $v r_{i}$. Thus, equation (5) should be written as follows:

$$
r(t)=n \cdot R(t) \cdot[Q(t)-V(t)] \cdot v r_{i} .
$$

If perturbations are purely random, then the law of distribution is usually taken as normal. In order to have reason to believe that the law of distribution deviates from the normal one, it is necessary to indicate the reasons why some values of a random variable take precedence over others. It is natural to consider a random variable $v r_{i}$ to be normally distributed by the law $N(a ; \sigma)$. If the distribution law is critical, then in each case a separate study should be conducted to determine the exact type of distribution law. Thus, the mean value of this magnitude should be close to one. As to mean square deviation, it should be selected on the basis of the study of the real process of selling goods in each case. We assume that the scatter of values of the number of sales $r_{i}$ from period to period in this case is within $30 \%$. The scatter within this framework will be ensured when $\sigma=0.09$. As a result, we obtain a random variable $v r_{i}$ distributed according to the law $N(1 ; 0.09)$.

Fig. 13 shows specific implementation of the value $v r_{i}$ with the distribution law $N(1 ; 0.09)$, as a period function.

This implementation of a random variable has the following parameters:

$$
\operatorname{mean}\left(v r_{i}\right)=1.0007, \min \left(v r_{i}\right)=0.7274, \max \left(v r_{i}\right)=1.2547,
$$

where "mean" is the average value.

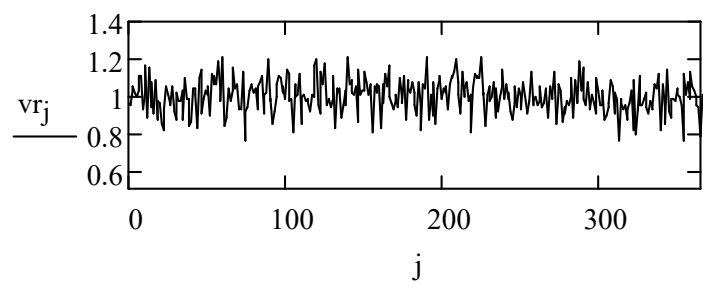

Fig. 13. Operational implementation of the variable $v r_{i}$ in the interval $i=\overline{0.365}$

The equation (7) should be similarly written as follows:

$$
s o(t)=\min \left[\begin{array}{l}
r_{i}^{*}\left(1+\frac{R m-R(t)}{R m}\right), \\
R m-R(t), S(t)
\end{array}\right] \cdot v s_{i},
$$

The distribution law for the random variable $v s_{i}$ describing the stochastic nature of the coefficient of delivery rate $s o_{i}$ from the wholesale warehouse to the retailer is defined as the distribution law $N(1 ; 0.08)$.

Fig. 14 shows the implementation of the value $v s_{i}$ as a period function with the distribution law $N(1 ; 0.08)$.

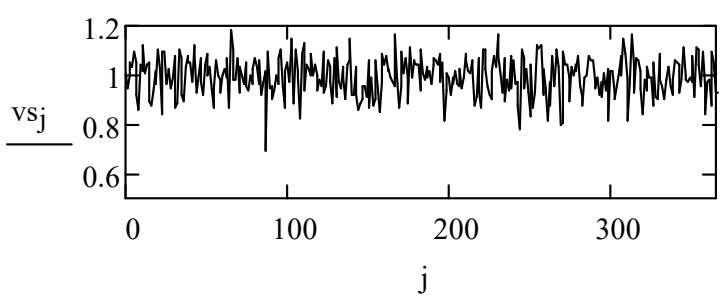

Fig. 14. Implementation of the variable $v s_{i}$ in the interval

$$
i=\overline{0.365}
$$

The implementation of the random variable $v s_{i}$ has the following meanings: $\operatorname{mean}\left(v s_{i}\right)=1.0033, \min \left(v s_{i}\right)=0.7949$, $\max \left(v s_{i}\right)=1.2277$.

The rate of manufacture, like any rate in the LS operation, is affected by noise. For the discrete-time form, equation (9) to account for noise should be written as follows:

$$
y_{i+1}=\left(y_{i}+\frac{y m-y_{i}}{t y}\right) \cdot v y_{i} .
$$

Suppose that the average production load is $90 \%$. In this case, the random variable $v y_{i}$ :

$$
v y_{i}=\left\{\begin{array}{l}
v y 1_{i}, v p 1_{i}<1.1, \\
1.1, \quad v p 1_{i} \geq 1.1
\end{array}\right.
$$

where $v y 1_{i}$ is the random variable with the distribution law $N(1 ; 0.08)$.

Fig. 15 shows specific implementation of the value $v y_{i}$ as a period function.

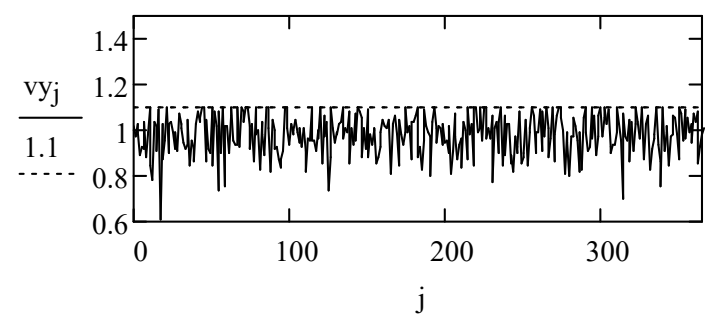

Fig. 15. Implementation of the variable $v y_{i}$ in the interval

$$
i=\overline{0.365}
$$

This implementation of the random variable $v y_{i}$ has the following parameters: $\operatorname{mean}\left(v p_{i}\right)=1.0022, \min \left(v p_{i}\right)=0.7415$, $\max \left(v p_{i}\right)=1.1$.

To account for the flow of random perturbations, formulas (5), (9), (11) are replaced with formulas (15), (16) and (17) corresponding to them. Comparison of the flows shown in Fig. 9, in the deterministic case (i. e. in the case corresponding to formulas (5), (9), (11)) and in the case of disturbances (i. e. in the case corresponding to formulas (14), (16), (17)) is shown in Fig. 16. Variables calculated in the presence of disturbances are indicated by the docking index "s".

Fig. 16 represents a case when the flow of disturbances is rather strong (from $30 \%$ ). The calculation by the formula (18) shows that for such large fluctuations as in Fig. 16, the effectiveness of the advertising campaign is more than halved. In real systems, a certain intermediate variant will be implemented between the left (fully defined) and right (strong disturbances) cases presented in Fig. 16. 

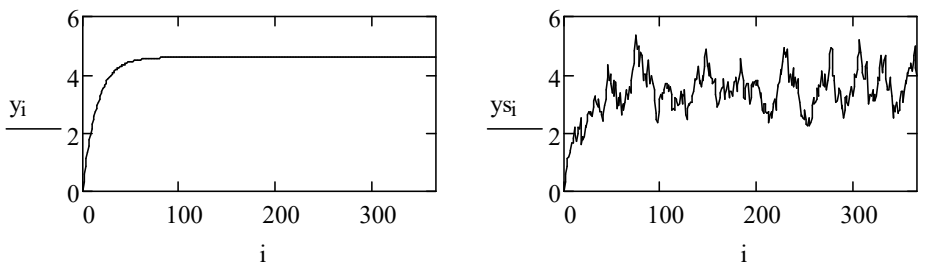

a

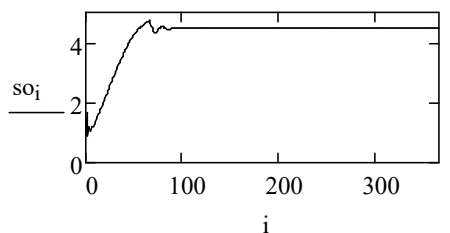

c
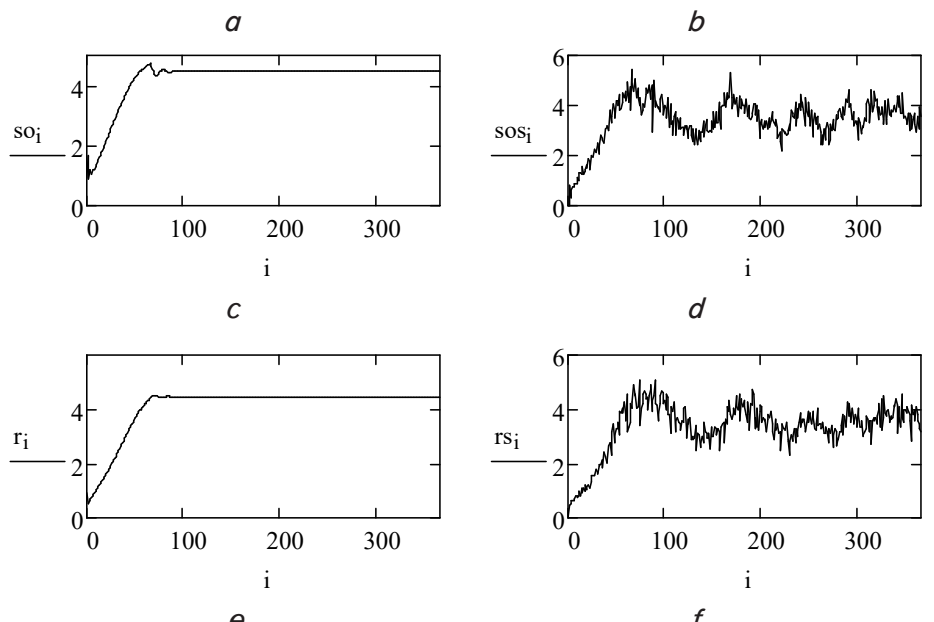

$d$

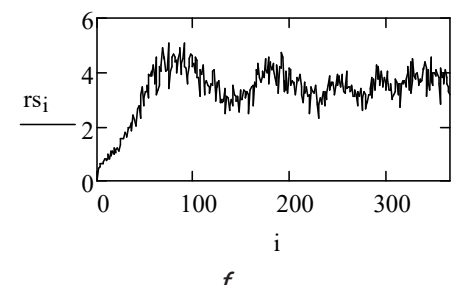

$f$

Fig. 16. Comparison of flows in LS: $a, c, e-$ in the deterministic case; $b, d, f-$ in the case of disturbances

\section{Discussion of the results}

To solve the problem of expanding the market niche of an enterprise, taking into account potential demand and creating an effective advertising campaign, an economic and mathematical model of the enterprise's production activity has been developed taking into account logistics and market demand. The paper proposes the formula (3), which determines the dependence of the number of potential consumers of products on advertising costs. This formula is a consequence of the assumption that the advertising campaign is described by a first-order differential delay equation (2). The dependence curve is shown to determine the maximum potential demand that will be achieved with constant advertising costs over a period of time. For the considered discrete-time model of potential demand as a result of the advertising campaign, the formula (4) was obtained, which is consistent with the first-order delay model [1].

For the logistics system, shown in Fig. 1 and described by equations (1)-(4), a mathematical model is developed that determines the operation of all other links of the LS, this is reflected by the system of equations (5)-(11). The model allows to determine: the inventory level in the retail trade (6), the rate of delivery from the wholesale warehouse to the retail trade (7), the production rate (9), the level of inventory in the wholesale warehouse (10), the net income of the enterprise (11).

Due to the fact that equation (5) contains the number of potential consumers $Q_{i}$, reflecting market demand for products, the mathematical model of LS allows us to investigate how the enterprise's advertising costs affect its profit. This is an advantage of the proposed method.

A methodology of determining the parameters of the optimal advertising campaign, for which the dynamics of all the main indicators of LS are calculated in the Mathcad package, allows the enterprise to plan production activities in real time. The results of the calculations are shown

in Fig. 4-12. The obtained values of economic indicators with and without averaging are almost identical.

The methodology is developed for two cases of the economic state of the enterprise:

- the enterprise produces homogeneous goods and a wholesale warehouse can fulfill the retail order for any amount of goods in the wholesale warehouse;

- the enterprise makes some products in assortment (for example, footwear). In this case, in the wholesale warehouse there should be some minimum stock of products.

Optimal advertising costs were determined (for these two options), accordingly the outlined conditions of these provisions are limitations on the use of the proposed methodology.

The influence of random environmental factors on the economic effectiveness of the advertising campaign has been investigated: the traffic flow may fluctuate depending on the availability and condition of vehicles, the flow of goods produced may change depending on the operation rate of the production unit, the sales flow of everyday goods is stochastic by nature. Taking into account the presence of "noise" in the flow characteristics, the random variable is introduced in equation (5) and it is proved that the perturbations have the form of a normal distribution law with the calculated parameters.

The studies conducted are more thorough than those previously considered in other studies on advertising, namely, the model considers the dependence of current demand on advertising with the fewest parameters that can be applied to any enterprise that produces one product type or poorly differentiated products.

\section{Conclusions}

1. A universal mathematical model of an advertising campaign is developed, which, unlike other models, allows to take into account the effect of advertising on current demand with the least number of parameters (two parameters). When empirically determining the parameters of this model, it can be applied to any enterprise that produces one type of product or weakly differentiated products. Based on this model, calculations for the dependence of potential demand on advertising costs were made. Numerical calculations show that, according to the accepted parameters of the logistics system, the maximum additional demand due to advertising cannot exceed the limit value.

2 . The system of mathematical equations for the proposed scheme of the logistics system of the enterprise, which describes the entire LS chain from the production link to the end consumer of products, is compiled. It contains an algebraic equation of growth in potential demand for products $\Delta Q r$ while increasing advertising costs $\Delta Z$ and, accordingly, a differential equation with a given initial condition. The proposed system also includes algebraic equations that describe such parameters as the rate of sale, the level of inventory in the retail trade, the rate of delivery of products from the wholesale warehouse to the retail point, the rate of production, the level of inventory in the wholesale warehouse, the net income of the enterprise. Time is considered as a discrete variable, the project has a planning horizon of T. For specific given parameters of the model, numerical values of the listed indicators are calculated. 
3. The optimization problems of determining the optimal costs of an advertising campaign are formulated and numerically solved. The calculations proved that these costs substantially depend on all parameters of the LS. Numerical calculations show that the effectiveness of an advertising campaign, subject to its optimality, can reach $351 \%$. This means that for each monetary unit spent on an advertising campaign, additional income of $\$ 3.51$ can be received.
4. The impact of random factors on the cost effectiveness of an advertising campaign is quantified. It is proved that in case of significant accidental influence of the external economic environment, when the disturbance flow is rather strong (from $30 \%$ ), the effectiveness of the advertising campaign is reduced more than twice. With less significant disturbances (less than $2 \%$ ), the effectiveness of the advertising campaign remains the same as in the absence of perturbations.

\section{References}

1. Forrester, J. W. (1958). Industrial Dynamics - A Major Breakthrough for Decision Makers. Harvard Business Review, 36 (4), 37-66. Available at: https://ru.scribd.com/doc/158721742/Industrial-Dynamics-A-Major-Breakthrough-for-Decision-Makers

2. Brajnik, G., Gabrielli, S. (2010). A Review of Online Advertising Effects on the User Experience. International Journal of Human-Computer Interaction, 26 (10), 971-997. doi: https://doi.org/10.1080/10447318.2010.502100

3. Lambrecht, A., Tucker, C. (2013). When Does Retargeting Work? Information Specificity in Online Advertising. Journal of Marketing Research, 50 (5), 561-576. doi: https://doi.org/10.1177/002224371305000508

4. Wang, T.-C., Chen, L. Y., Chen, Y.-H. (2008). Applying Fuzzy PROMETHEE Method for Evaluating IS Outsourcing Suppliers. 2008 Fifth International Conference on Fuzzy Systems and Knowledge Discovery. doi: https://doi.org/10.1109/fskd.2008.506

5. Yuan, S., Wang, J., Zhao, X. (2013). Real-time bidding for online advertising: measurement and analysis. arXiv. Available at: https:// arxiv.org/pdf/1306.6542.pdf

6. He, X., Prasad, A., Sethi, S. P. (2009). Cooperative Advertising and Pricing in a Dynamic Stochastic Supply Chain: Feedback Stackelberg Strategies. Production and Operations Management. 18 (1), 78-94. doi: https://doi.org/10.1111/j.1937-5956.2009.01006.x

7. Du, H., Xu, Y. (2012). Research on Multi-Objective Optimization Decision Model of Web Advertising - Takes Recruitment Advertisement as an Example. International Journal of Advancements in Computing Technology, 4 (10), 329-336. doi: https:// doi.org/10.4156/ijact.vol4.issue10.39

8. Guha, S., Cheng, B., Francis, P. (2010). Challenges in measuring online advertising systems. Proceedings of the 10th Annual Conference on Internet Measurement - IMC '10. doi: https://doi.org/10.1145/1879141.1879152

9. Marques, C. P., Almeida, D. (2013). A Path Model of Attitudinal Antecedents of Green Purchase Behaviour. ECONOMICS \& SOCIOLOGY, 6 (2), 135-144. doi: https://doi.org/10.14254/2071-789x.2013/6-2/12

10. Xie, J., Neyret, A. (2009). Co-op advertising and pricing models in manufacturer-retailer supply chains. Computers \& Industrial Engineering, 56 (4), 1375-1385. doi: https://doi.org/10.1016/j.cie.2008.08.017

11. Tsou, C.-S., Fang, H.-H., Lo, H.-C., Huang, C.-H. (2009). A study of cooperative advertising in a manufacturer-retailer supply chain. International Journal of Information and Management Sciences, 20, 15-26.

12. Wei, Y., Choi, T.-M. (2010). Mean-variance analysis of supply chains under wholesale pricing and profit sharing schemes. European Journal of Operational Research, 204 (2), 255-262. doi: https://doi.org/10.1016/j.ejor.2009.10.016

13. Kogler, C., Rauch, P. (2018). Discrete event simulation of multimodal and unimodal transportation in the wood supply chain: a literature review. Silva Fennica, 52 (4). doi: https://doi.org/10.14214/sf.9984

14. Siderska, J. (2016). Application of tecnomatix plant simulation for modeling production and logistics processes. Business, Management and Education, 14 (1), 64-73. doi: https://doi.org/10.3846/bme.2016.316

15. Bremer, P. (2018). Towards a reference model for the cold chain. The International Journal of Logistics Management, 29 (3), 822-838. doi: https://doi.org/10.1108/ijlm-02-2017-0052

16. Farahani, R. Z., Rezapour, S., Kardar, L. (2011). Logistics Operations and Management: Concepts and Models. Elsevier, 486. doi: https://doi.org/10.1016/c2010-0-67008-8

17. Voronin, A. V., Gunko, O. V. (2013). Discrete Model of Market Adaptation. Business Inform, 4, 158-162. Available at: http://nbuv. gov.ua/UJRN/binf_2013_4_30

18. Titarenko, D. V. (2011). Model of conduct of users of the same type products. Business Inform, 10, 99-100. Available at: https:// www.business-inform.net/annotated-catalogue/?year=2011\&abstract=2011_10_0\&lang=ru\&stqa=23

19. Gvozdetskaya, I. V., Ostapchuk, O. V. (2011). Analysis of Approaches to Modeling Industrial Enterprise Management Processes. Business Inform, 5, 79-80. Available at: https://www.business-inform.net/annotated-catalogue/?year=2011\&abstract=2011_05_1 \&lang $=$ ua\&stqa $=23$

20. Gorskii, A. A., Kolpakova, I. G., Lokshin, B. Ya. (1998). Dynamical model of the process of production, storage, and sale of daily demand goods. Izvestiya Rossiyskoy Akademii Nauk. Teoriya i sistemy upravleniya, 1, 144-148. Available at: https://www.elibrary. $\mathrm{ru} / \mathrm{item}$. asp?id=14945102

21. Sherstennykov, Yu. V., Rudianova, T. M. (2014). Modeliuvannia mekhanizmiv vplyvu na tempy prodazhu produktsiyi pidpryiemstva. Aktualni problemy ekonomiky, 1, 551-559.

22. Sherstennykov, Y. V., Rudyanova, T. M. (2013). Model for planning of small or medium enterprise project. Actual Problems of Economics, 7, 205-216. Available at: http://nbuv.gov.ua/UJRN/ape_2013_7_25

23. Sherstennykov, Yu. V. (2011). Model zhyttievoho tsyklu proektu i sezonnosti v roboti maloho pidpryiemstva. Aktualni problemy ekonomiky, 8, 334-347.

24. Sherstennikov, Yu. V., Rudianova, T. M., Brytska, V. Yu. (2018). The Model Optimization of Production Capacity of Enterprise. Business Inform, 6, 186-192. Available at: http://nbuv.gov.ua/UJRN/binf_2018_6_27 